Article

\title{
Adipic Acid Route: Oxidation of Cyclohexene vs. Cyclohexane
}

\author{
Ana P. C. Ribeiro ${ }^{1}\left(\mathbb{D}\right.$, Elisa Spada ${ }^{2}$, Roberta Bertani ${ }^{2}(\mathbb{D})$ and Luísa M. D. R. S. Martins ${ }^{1, *(D)}$ \\ 1 Centro de Química Estrutural and Departamento de Engenharia Química, Instituto Superior Técnico, \\ Universidade de Lisboa, Av. Rovisco Pais, 1049-001 Lisboa, Portugal; apribeiro@tecnico.ulisboa.pt \\ 2 Department of Industrial Engineering, University of Padova, 35122 Padova, Italy; \\ elisaspada91@hotmail.it (E.S.); roberta.bertani@unipd.it (R.B.) \\ * Correspondence: luisammartins@tecnico.ulisboa.pt; Tel.: +351-218-419-389
}

Received: 20 November 2020; Accepted: 8 December 2020; Published: 10 December 2020

\begin{abstract}
A cleaner alternative to the current inefficient oxidation of cyclohexane to adipic acid is presented. Direct oxidation of neat cyclohexene by aq. hydrogen peroxide to adipic acid is selectively achieved in good yield $(46 \%)$, in the presence of the recyclable C-homoscorpionate iron(II) complex $\left[\mathrm{FeCl}_{2}\left\{\mathrm{k}^{3}-\mathrm{HC}(\mathrm{pz})_{3}\right\}\right](\mathrm{pz}=$ pyrazol-1-yl) and microwave irradiation, by a nitrous oxide-free protocol.
\end{abstract}

Keywords: cyclohexene; adipic acid; oxidation; nitrous oxide; C-scorpionate; iron; microwave; ionic liquid; recyclable

\section{Introduction}

Adipic acid (AA) is a highly relevant commodity produced at a large scale (over 3.5 mio metric tons/year and growing by ca. 5\%/year) [1,2] worldwide, as it constitutes a building block for several industrial processes. It is mostly used for the synthesis of Nylon- 6,6 polyamide; therefore, the rising demand for engineered plastics requires increased production of AA.

Currently, adipic acid is mainly obtained by an inefficient and environmentally harmful two-step process $[1,3]$ involving catalytic cyclohexane oxidation to cyclohexanol and cyclohexanone mixture followed by its oxidation with nitric acid. Thus, AA production is the largest source of industrial greenhouse gas $\mathrm{N}_{2} \mathrm{O}$ emissions ( $300 \mathrm{~kg}$ of $\mathrm{N}_{2} \mathrm{O}$ per ton of produced adipic acid) [2], which corresponds to $8 \%$ of the worldwide anthropogenic $\mathrm{N}_{2} \mathrm{O}$ emissions. In addition, cyclohexane oxidation is a low-efficiency industrial process, with conversions usually lower than $10 \%$ to ensure a selectivity of $80 \%$ for the cyclohexanol/cyclohexanone mixture [1,4]. Therefore, the development of a sustainable catalytic system for such a large-scale process is a task of high significance.

In this work, we present a nitrous oxide-free alternative oxidative process (Scheme 1a), using cyclohexene (instead of cyclohexane) as substrate, the environmentally acceptable aqueous $\mathrm{H}_{2} \mathrm{O}_{2}$ as oxidant, and employing a known [5-7] efficient homogeneous catalyst for the oxidation of cyclohexane, the hydrotris(pyrazol-1-yl)methane $\mathrm{Fe}(\mathrm{II})$ complex $\left[\mathrm{FeCl}_{2}\left\{\mathrm{k}^{3}-\mathrm{HC}(\mathrm{pz})_{3}\right\}\right]$ (pz = pyrazolyl) (Scheme 1b) [8], not yet applied for alkene oxidations.

The iron compound exhibits a tetragonal pyramid coordination polyhedron bearing one of the donor nitrogen pyrazolyl atoms at the axial position and where the iron atom has a vacant coordination site that could be easily occupied by a substrate [9]. In addition, this complex is easy (one step) to synthesize [8] at r.t. and requires the simplest ligand of the tris(pyrazol-1-yl)methane carbon scorpionate class. C-scorpionate tripodal ligands, with their three $\mathrm{N}$ atoms of the pyrazolyl moieties, are recognized to be involved in key catalytic oxidative processes with aq. hydrogen peroxide [8]. Moreover, $\left[\mathrm{FeCl}_{2}\left\{\mathrm{~K}^{3}-\mathrm{HC}(\mathrm{pz})_{3}\right\}\right]$ displays high solubility in aqueous solvents [7], favoring the use of this oxidant. Furthermore, the alternative energy source of microwaves (MW) was chosen, aiming at 
enhancing product yield and selectivity while being more energy-efficient and economic relative to conventional thermal heating methods (e.g., oil bath) [10-12].

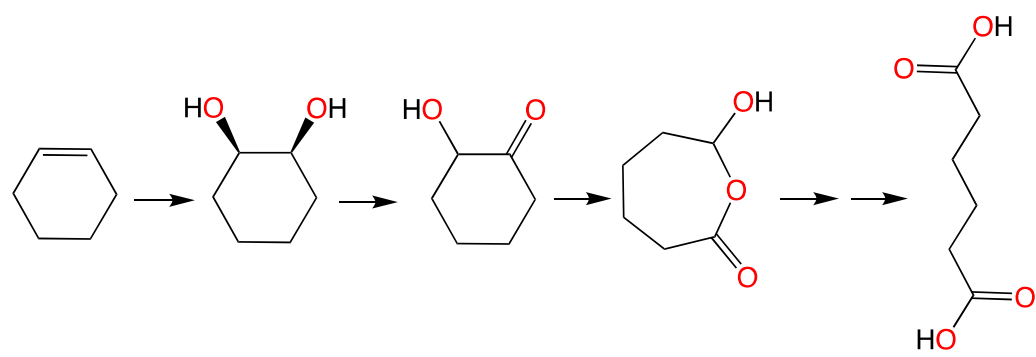

(a)

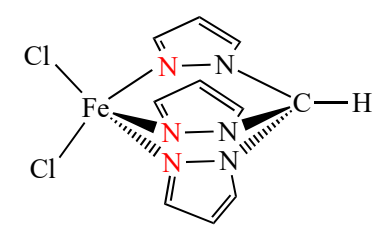

(b)

Scheme 1. (a) Oxidation of cyclohexene to adipic acid catalyzed by $\left[\mathrm{FeCl}_{2}\left\{\mathrm{k}^{3}-\mathrm{HC}(\mathrm{pz})_{3}\right\}\right] ;$ (b) $\left[\mathrm{FeCl}_{2}\right.$ $\left.\left\{\kappa^{3}-\mathrm{HC}(\mathrm{pz})_{3}\right\}\right]$ structure.

$\left[\mathrm{FeCl}_{2}\left\{\mathrm{k}^{3}-\mathrm{HC}(\mathrm{pz})_{3}\right\}\right]$ has proven its catalytic activity for the selective peroxidative oxidation of cyclohexane to the cyclohexanone and cyclohexanol mixture (up to ca. 35\% max overall yield) [6-9,13-17] but neither further oxidized species were formed under the used conditions, nor was the complex assayed with alkene substrates.

Cyclohexene oxidative cleavage with $\mathrm{H}_{2} \mathrm{O}_{2}$ has been used by Noyori et al. $[18,19]$ as one of the most promising and environmentally tolerable routes to adipic acid, although the price of hydrogen peroxide impaired its industrial implementation. Thus, finding a suitable catalyst would be crucial for the sustainability of this process.

\section{Results and Discussion}

The present $\left[\mathrm{FeCl}_{2}\left\{\mathrm{k}^{3}-\mathrm{HC}(\mathrm{pz})_{3}\right\}\right]$-based new catalytic system afforded adipic acid directly from the selective oxidation (by $\mathrm{H}_{2} \mathrm{O}_{2}, 4.2$ equiv.) of cyclohexene in a good yield (46\%, Figure 1) after $24 \mathrm{~h}$ of MW irradiation at $60^{\circ} \mathrm{C}$, without the need of nitric acid, another strong oxidant, additive or solvent (see experimental, ESI). Moreover, AA precipitates from the reaction mixture, allowing its separation by filtration and prompt isolation in a pure form (see Figure S1, ESI).

cis-cyclohexane-1,2-diol, its $\alpha$-hydroxy-ketone derivative and the lactone 7-hydroxyoxepan-2-one were also detected by GC-MS and ${ }^{1} \mathrm{H}$ and ${ }^{13} \mathrm{C}$ NMR techniques. The time evolution of the reaction mixture composition is depicted in Figure 1.

The unprecedented use of low-power MW irradiation in the present route to AA proved the ability of this method to reduce the reaction time and energy consumption, thus being advantageous over the conventional heating method. For example, $24 \mathrm{~h}$ of water bath heating at $60^{\circ} \mathrm{C}$ of the above-mentioned reaction mixture led exclusively to cis-cyclohexane-1,2-diol.

The effect of the addition of a free radical scavenger $\left(\mathrm{CBrCl}_{3}\right.$ or $\left.\mathrm{Ph}_{2} \mathrm{NH}\right)$ in the peroxidative oxidation medium was evaluated, leading to a drastic decrease in all product yields, thus indicating the radical involvement in the first step of the oxidation process. Then, for Baeyer-Villiger oxidation and hydrolyses, follow $[18,19]$ (Scheme 1).

The stability of the homogeneous catalyst $\left[\mathrm{FeCl}_{2}\left\{\mathrm{k}^{3}-\mathrm{HC}(\mathrm{pz})_{3}\right\}\right]$ was assessed at the end of the MW-assisted oxidation reaction. The far-infrared spectrum of the used $\left[\mathrm{FeCl}_{2}\left\{\mathrm{~K}^{3}-\mathrm{HC}(\mathrm{pz})_{3}\right\}\right]$ (Figure S2, ESI) shows that the genuine $v(\mathrm{Fe}-\mathrm{Cl})$ bands [7] are maintained after the catalytic oxidation reaction. However, its activity in a further catalytic cycle was minimal. The catalyst observed deactivation may be due to the coordination of a water molecule (e.g., from the oxidant solution) to the free site of the iron coordination sphere, thus blocking the previously vacant position and impairing the access of the substrate to it. 
The potential recyclability of the iron catalyst was explored by using room-temperature ionic liquids, ILs, as reaction media. Tetradecyltrihexylphosphonium dicyanamide $\left(\left[\mathrm{P}_{6,6,6,14}\right]\left[\mathrm{N}(\mathrm{CN})_{2}\right]\right.$, CYPHOS $^{\circledR} 105$ ), hexylmethylimidazolium bis(trifluoromethanesulfonyl)imide, $\left[\mathrm{C}_{6}\right.$ mim] $\left[\mathrm{NTf}_{2}\right]\left[\mathrm{NTf}_{2}=\right.$ $\left.\mathrm{N}\left(\mathrm{SO}_{2} \mathrm{CF}_{3}\right)_{2}\right]$ and methyltrioctylammonium chloride $\left(\left\{\left[\mathrm{CH}_{3}\left(\mathrm{CH}_{2}\right)_{7}\right]_{3} \mathrm{NCH}_{3}\right\} \mathrm{Cl}\right.$, Aliquat $\left.{ }^{\circledR} 336\right)$, the last one known as an efficient phase transfer catalyst for the oxidation of cyclohexene [18], were chosen in view of their ability to act as suitable solvents for $\left[\mathrm{FeCl}_{2}\left\{\mathrm{k}^{3}-\mathrm{HC}(\mathrm{pz})_{3}\right\}\right]$. The conversion of cyclohexene exhibited a marked dependency on the IL used, as depicted in Figure 2.

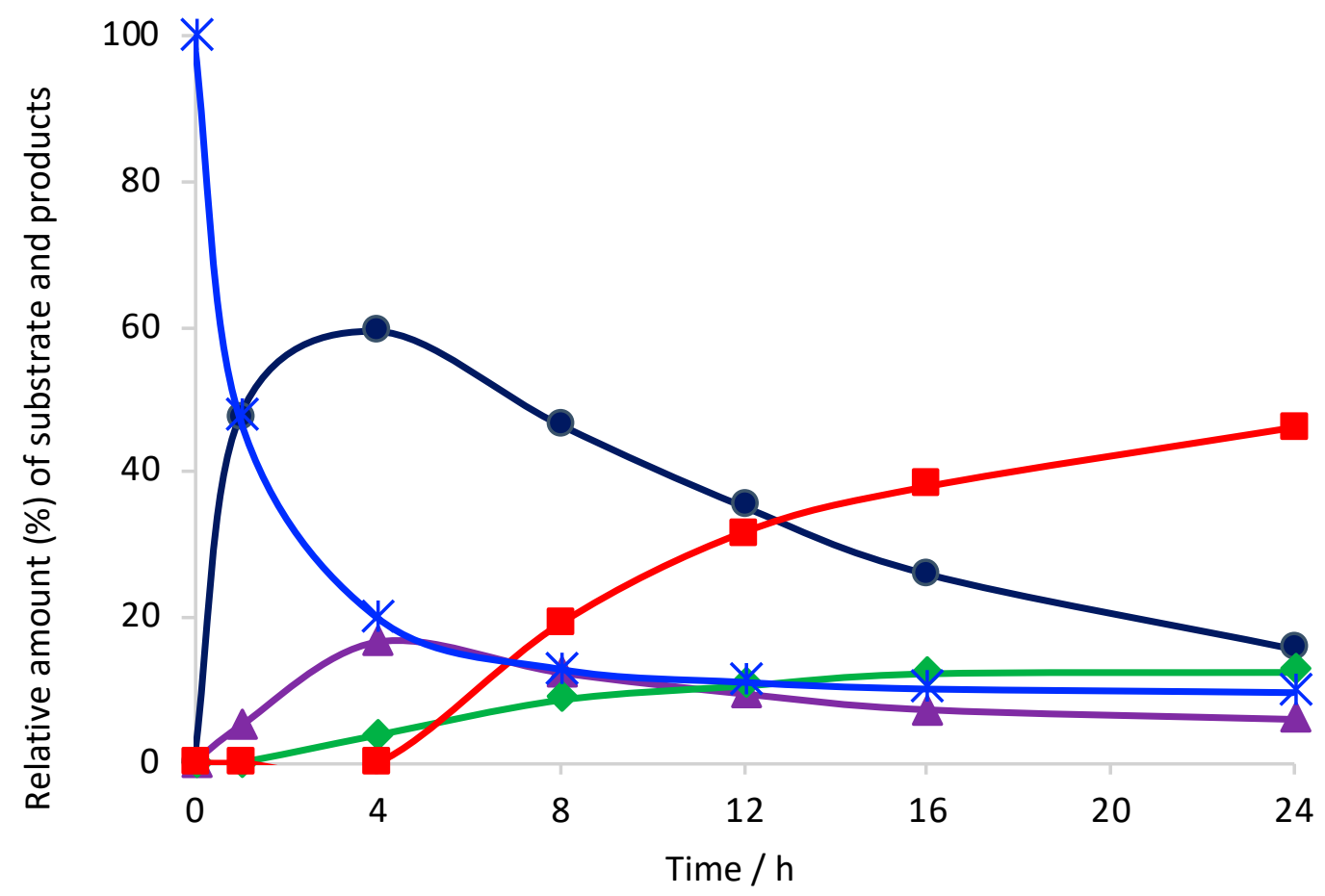

Figure 1. Reaction time effect on the relative amount (molar \%) of cyclohexene $\left(^{*}\right)$ and of products,

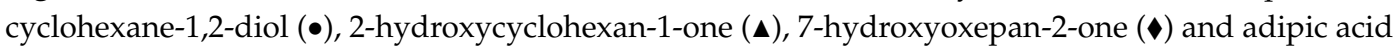
(घ), obtained by $\mathrm{MW}$-assisted oxidation of neat cyclohexene by $\mathrm{H}_{2} \mathrm{O}_{2}$, at $60{ }^{\circ} \mathrm{C}$, catalyzed by $15 \mu \mathrm{mol}$ of $\left[\mathrm{FeCl}_{2}\left\{\mathrm{k}^{3}-\mathrm{HC}(\mathrm{pz})_{3}\right\}\right]$.

The best AA yield (38\%), similar to the one achieved in solvent-free conditions, was obtained in the hydrophilic $\left[\mathrm{P}_{6,6,6,14}\right][\mathrm{NCN}]$ (Figure 2), where the dicyanamide anion interacts very efficiently with $\left[\mathrm{FeCl}_{2}\left\{\mathrm{k}^{3}-\mathrm{HC}(\mathrm{pz})_{3}\right\}\right]$, towards its interaction with the coordination sphere of the iron(II) center, as previously discovered by our team [9].

Furthermore, the use of the chosen ionic liquids provided more stable reaction media, allowing easy separation of the catalyst and IL from the organic products and substrate (extracted with diethyl ether). Indeed, a triphasic system is promptly achieved by extraction, as illustrated in Figure 3 for $\left[\mathrm{P}_{6,6,6,14}\right][\mathrm{NCN}]$ : the upper ethereal phase containing the organics (1), the middle aq. $\mathrm{H}_{2} \mathrm{O}_{2}$ phase (2) and the bottom one formed by the $\left[\mathrm{FeCl}_{2}\left\{\mathrm{~K}^{3}-\mathrm{HC}(\mathrm{pz})_{3}\right\}\right]$ complex in $\left[\mathrm{P}_{6,6,6,14}\right][\mathrm{NCN}](3)$. Therefore, the catalyst reuse is addressed in IL medium.

$\left[\mathrm{FeCl}_{2}\left\{\mathrm{~K}^{3}-\mathrm{HC}(\mathrm{pz})_{3}\right\}\right]$ maintained its catalytic efficiency to produce adipic acid during at least five consecutive cycles (Figure 4 ) in $\left[\mathrm{P}_{6,6,6,14}\right][\mathrm{NCN}]$ with an easy workup.

Previous IL systems [20] coupled with hydrogen peroxide for the oxidation of cyclohexene to adipic acid employ heavy metals, mainly tungsten (e.g., $\mathrm{H}_{2} \mathrm{WO}_{4}$ ), with a catalytic activity highly dependent on the reaction medium acidity. Advantageously, the use of C-scorpionate $\left[\mathrm{FeCl}_{2}\left\{\mathrm{k}^{3}-\mathrm{HC}(\mathrm{pz})_{3}\right\}\right]$ catalyst eliminates such requirements. 


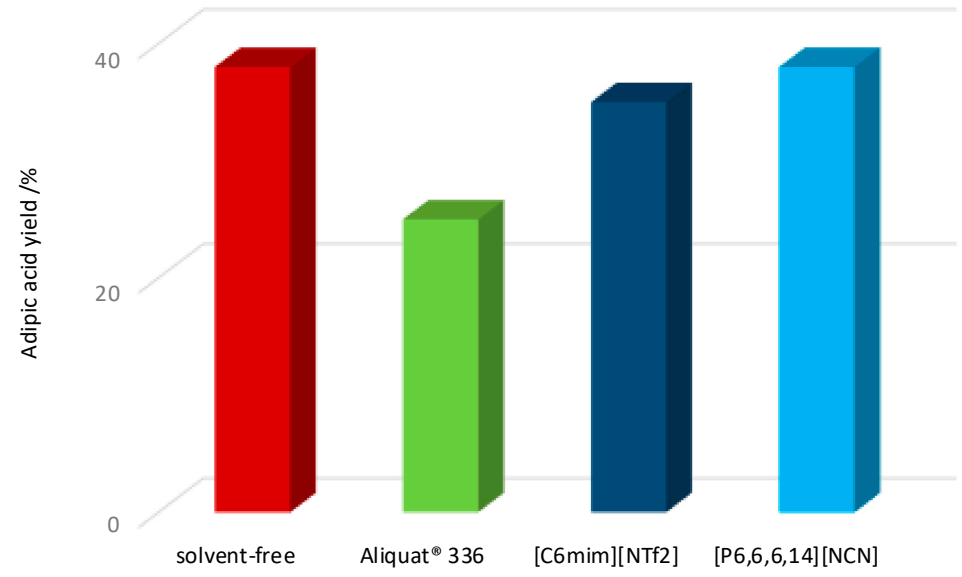

Figure 2. Effect of the reaction medium on the yield of AA for the MW-assisted cyclohexene oxidation, with $\mathrm{H}_{2} \mathrm{O}_{2}, 16 \mathrm{~h}$ at $60{ }^{\circ} \mathrm{C}$, catalyzed by $\left[\mathrm{FeCl}_{2}\left\{\mathrm{\kappa}^{3}-\mathrm{HC}(\mathrm{pz})_{3}\right\}\right]$.

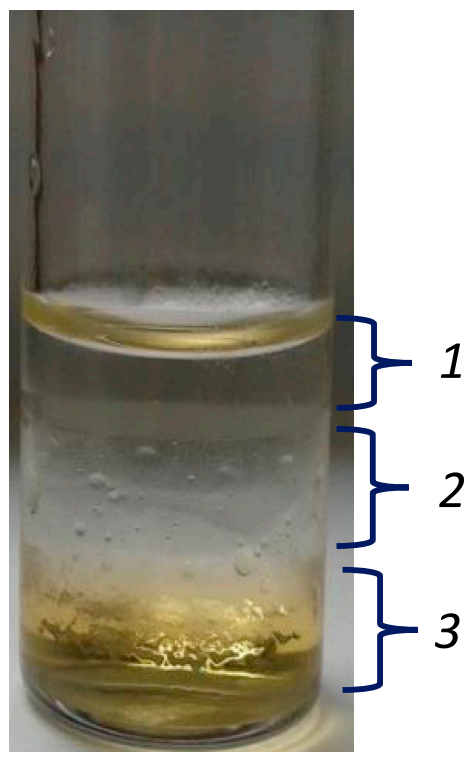

Figure 3. Recovery of $\left[\mathrm{FeCl}_{2}\left\{\mathrm{k}^{3}-\mathrm{HC}(\mathrm{pz})_{3}\right\}\right]$ complex in $\left[\mathrm{P}_{6,6,6,14}\right][\mathrm{NCN}]$.

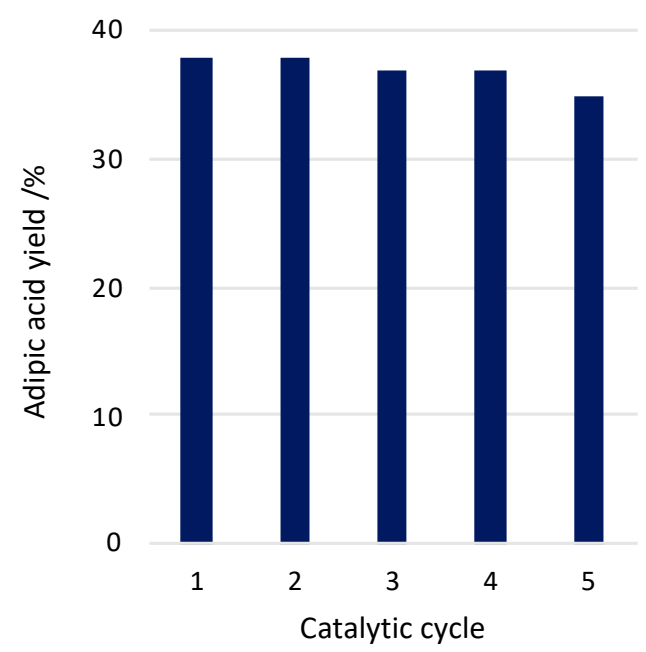

Figure 4. Effect of the catalyst recycling on the yield of AA for the microwave-assisted cyclohexene oxidation (16 h) with $\mathrm{H}_{2} \mathrm{O}_{2}$, at $60{ }^{\circ} \mathrm{C}$, catalyzed by $\left[\mathrm{FeCl}_{2}\left\{\mathrm{~K}^{3}-\mathrm{HC}(\mathrm{pz})_{3}\right\}\right]$. 


\section{Materials and Methods}

All the reagents and solvents were purchased and used without further treatment. $\left[\mathrm{FeCl}_{2}\left\{\mathrm{~K}^{3}-\right.\right.$ $\left.\mathrm{HC}(\mathrm{pz})_{3}\right\}$ ] was synthetized as described in the literature [8]. Double distilled and de-ionized water were used for all preparations and analyses.

The microwave-assisted oxidation reactions were performed using G10 tubes (as described in the instruction manual) in an Anton Paar Monowave 300 reactor fitted with an IR $\left( \pm 1^{\circ} \mathrm{C}\right)$ temperature detector and a rotational system.

A Perkin Elmer Clarus $600 \mathrm{C}$ instrument (carrier gas: helium) was used for GC-MS analyses. The apparatus was equipped with two capillary columns (SGE BPX5; $30 \mathrm{~m} \times 0.32 \mathrm{~mm} \times 25 \mathrm{~mm}$ ). A part of the equipment has an EI-MS (electron impact) detector and other has an FID detector. Moreover, $330{ }^{\circ} \mathrm{C}$ was the temperature used for injection. In each run, the initial temperature of $50{ }^{\circ} \mathrm{C}$ was increased $10{ }^{\circ} \mathrm{C}$ per minute, until $330^{\circ} \mathrm{C}$ was reached. All reaction products were identified in the chromatograms by comparing their retention times with the presented by known reference compounds. The obtained fragmentation patterns of the products' mass spectra were compared to the NIST spectral library database.

Fisons Instruments GC 8000 series gas chromatograph with an FID detector was the other gas chromatograph (GC) used. All measurements were carried out using it with one capillary column (DBWAX, column length: $30 \mathrm{~m}$; internal diameter: $0.32 \mathrm{~mm}$ ). The carrier gas used was helium. The products formed in the reaction were identified by comparison of retention times with standard samples.

The NMR spectra $\left({ }^{1} \mathrm{H}\right.$ and $\left.{ }^{13} \mathrm{C}\right)$ were run at room temperature on a Bruker Advance II +300 (UltraShield ${ }^{\mathrm{TM}}$ Magnet) spectrometer. The operating frequencies were 300.130 and $75.468 \mathrm{MHz}$ for proton and carbon-13, respectively. The internal reference was tetramethylsilane and the chemical shifts are reported in ppm.

Infrared spectra $\left(4000-400 \mathrm{~cm}^{-1}\right)$ and far-infrared spectra $\left(400-200 \mathrm{~cm}^{-1}\right)$ were recorded on a Vertex 70 (Bruker) instrument in $\mathrm{KBr}$ or cesium iodide pellets, respectively.

The elemental analyses were all carried out by LAIST-Microanalytical Service of the Instituto Superior Técnico.

\section{General Procedure for the Oxidation of Cyclohexene by Hydrogen Peroxide}

The MW-assisted oxidation of cyclohexene was generally performed as follows: the weighed amounts of $\left[\mathrm{FeCl}_{2}\left\{\mathrm{k}^{3}-\mathrm{HC}(\mathrm{pz})_{3}\right\}\right](15 \mu \mathrm{mol})$, cyclohexane $(12.2 \mathrm{mmol})$ and $\mathrm{H}_{2} \mathrm{O}_{2}(30 \% \mathrm{w} / \mathrm{w}$ aqueous solution) (4.0-5.0 mol. equiv. vs. substrate) were introduced into the G10 tube, closed, placed inside the microwave reactor and continuously stirred and subjected to low-power $(5-50 \mathrm{~W})$ irradiation for the desired $\left(50-100{ }^{\circ} \mathrm{C}\right)$ temperature and reaction time $(1-24 \mathrm{~h})$. When used, the ionic liquid $\left(1.5 \mathrm{~cm}^{3}\right)$ was added to the above Pyrex tube. After the reaction, the organics were extracted (diethyl ether, $1.0 \mathrm{~cm}^{3}$ ) and samples used for GC or GC-MS analysis or evaporated and dissolved in $\mathrm{CDCl}_{3}$ to be analyzed by ${ }^{1} \mathrm{H}$ or ${ }^{13} \mathrm{C}$ NMR spectroscopy. The yield of oxidation products (relatively to cyclohexene) was established using the suitable internal standards. Blank (Fe-free system) tests were also performed.

Recyclability studies using the catalyst in the IL medium were investigated. Each cycle was initiated after the preceding one by the addition of new portions of all other reagents needed. At the end of each run, the procedure was identical to the abovementioned, and the ionic liquid (with the catalyst) was recovered simply by drying overnight in vacuum at $60^{\circ} \mathrm{C}$.

\section{Conclusions}

In summary, the $\left[\mathrm{FeCl}_{2}\left\{\mathrm{k}^{3}-\mathrm{HC}(\mathrm{pz})_{3}\right\}\right]$-based catalytic system provides an effective route to oxidize cyclohexene to adipic acid with an efficiency $(46 \%$, Figure 1$)$ that overcomes the $\mathrm{H}_{2} \mathrm{O}_{2}$ price issue $[18,19]$. Moreover, very low catalyst load, environmentally benign, mild conditions, the use of the alternative MW energy source, solvent-free system, cheap, available and non-toxic metal as catalyst and a facile 
work-up are significant advantages of the present system. To the best of our knowledge, this work reports the first time that a C-scorpionate complex has been used as a catalyst for cyclohexene oxidation, either in homogenous or unconventional (IL) conditions, and constitutes a promising step towards the design of a sustainable $\left(\mathrm{N}_{2} \mathrm{O}\right.$-free) catalytic process for this industrially important reaction.

Further optimizations and mechanism investigations will be performed in view of the promising results achieved.

Supplementary Materials: The following are available online at http://www.mdpi.com/2073-4344/10/12/1443/s1, Figure S1: ${ }^{1} \mathrm{H}$ NMR spectrum of isolated adipic acid in DMSO, Figure S2: Far infrared spectrum of $\left[\mathrm{FeCl}_{2}\left\{\mathrm{~K}^{3}-\right.\right.$ $\left.\left.\mathrm{HC}(\mathrm{pz})_{3}\right\}\right]$ after acting as catalyst for the MW-assisted oxidation reaction of cyclohexene with $\mathrm{H}_{2} \mathrm{O}_{2}$.

Author Contributions: Conceptualization, A.P.C.R. and L.M.D.R.S.M.; investigation, E.S. and A.P.C.R.; writing - original draft preparation, E.S.; writing-review and editing, L.M.D.R.S.M.; supervision, A.P.C.R. and R.B. All authors have read and agreed to the published version of the manuscript.

Funding: This research was partially funded by Fundação para a Ciência e Tecnologia through UIDB/00100/2020 project of Centro de Química Estrutural. A.P.C.R. thanks Instituto Superior Técnico for the Scientific Employment contract IST-ID/119/2018.

Conflicts of Interest: The authors declare no conflict of interest.

\section{References}

1. Ullmann's Encyclopedia of Industrial Chemistry, 6th ed.; Wiley-VCH: Weinheim, Germany, 1999-2016.

2. Adipic acid (ADPA). World Market Outlook and Forecast up to 2020; Merchant Research and Consulting: Birmingham, UK, 2016.

3. Hermans, I.; Jacobs, P.A.; Peeters, J. To the core of autocatalysis in cyclohexane autoxidation. Chem. Eur. J. 2006, 12, 4229-4240. [CrossRef] [PubMed]

4. Van de Vyver, S.; Román-Leshkov, Y. Emerging catalytic processes for the production of adipic acid. Catal. Sci. Technol. 2013, 3, 1465-1479. [CrossRef]

5. Martins, L.M.D.R.S.; Pombeiro, A.J.L. Tris(pyrazol-1yl) methane metal complexes for catalytic mild oxidative functionalizations of alkanes, alkenes and ketones. Co-ord. Chem. Rev. 2014, 265, 74-88. [CrossRef]

6. Martins, L.M.D.R.S. C-scorpionate complexes: Ever young catalytic tools. Co-ord. Chem. Rev. 2019, 396, 89-102. [CrossRef]

7. Ribeiro, A.P.C.; Martins, L.M.D.R.S.; Pombeiro, A.J.L. N2O-free single-pot conversion of cyclohexane to adipic acid catalysed by an iron(II) scorpionate complex. Green Chem. 2017, 19, 1499-1501. [CrossRef]

8. Silva, T.F.S.; Alegria, E.C.B.A.; Martins, L.M.D.R.S.; Pombeiro, A.J.L. Scorpionate vanadium, iron and copper complexes as selective catalysts for the peroxidative oxidation of cyclohexane under mild conditions. Adv. Synth. Catal. 2008, 350, 706-716. [CrossRef]

9. Ribeiro, A.P.C.; Martins, L.M.D.R.S.; Kuznetsov, M.L.; Pombeiro, A.J.L. Tuning cyclohexane oxidation: Combination of microwave irradiation and ionic liquid with the C-scorpionate $[\mathrm{FeCl} 2(\mathrm{Tpm})]$ catalyst. Organometallics 2017, 36, 192-198. [CrossRef]

10. Zhao, B.Z.; Han, D.K. The N-H functional group in organometallic catalysis. Angewv. Chem. Int. Ed. 2013, 52, 4744-4788. [CrossRef] [PubMed]

11. Dudley, G.B.; Richert, R.; Stiegman, A.E. On the existence of and mechanism for microwave-specific reaction rate enhancement. Chem. Sci. 2015, 6, 2144-2152. [CrossRef] [PubMed]

12. Ribeiro, A.P.C.; Martins, L.M.D.R.S.; Hazra, S.; Pombeiro, A.J.L. Catalytic oxidation of cyclohexane with hydrogen peroxide and a tetracopper(II) complex in an ionic liquid. Comptes Rendus Chim. 2015, 18, 758-765. [CrossRef]

13. Martins, L.M.D.R.S.; Martins, A.; Alegria, E.C.B.A.; Carvalho, A.P.; Pombeiro, A.J.L. Efficient cyclohexane oxidation with hydrogen peroxide catalysed by a C-scorpionate iron(II) complex immobilized on desilicated MOR zeolite. Appl. Catal. A 2013, 464-465, 43-50. [CrossRef]

14. Martins, L.M.D.R.S.; Almeida, M.P.; Carabineiro, S.A.C.; Figueiredo, J.L.; Pombeiro, A.J.L. Heterogenisation of a C-scorpionate $\mathrm{Fe}(\mathrm{II})$ complex in carbon materials for cyclohexane oxidation with hydrogen peroxide. Chem CatChem 2013, 5, 3847-3856. [CrossRef] 
15. Martins, L.M.D.R.S.; Pombeiro, A.J.L. Water-soluble C-scorpionate complexes: Catalytic and biological applications. Eur. J. Inorg. Chem. 2016, 2236-2252. [CrossRef]

16. Ribeiro, A.P.C.; Martins, L.M.D.R.S.; Carabineiro, S.A.C.; Buijnsters, J.G.; Figueiredo, J.L.; Pombeiro, A.J.L. Heterogenised C-scorpionate iron(II) complex on nanostructured carbon materials as catalysts for microwave-assisted oxidation reactions. ChemCatChem 2018, 10, 1821-1828. [CrossRef]

17. Van-Dúnem, V.; Carvalho, A.P.; Martins, L.M.D.R.S.; Martins, A. Improved cyclohexane oxidation catalyzed by a heterogenised iron(II) complex on hierarchical Y zeolite through surfactant mediated technology. ChemCatChem 2018, 10, 4058-4066. [CrossRef]

18. Sato, K.; Aoki, M.; Noyori, R. A “Green” Route to Adipic Acid: Direct Oxidation of Cyclohexenes with 30 Percent Hydrogen Peroxide. Science 1998, 281, 1646-1647. [CrossRef]

19. Noyori, R.; Aoki, M.; Sato, K. Green oxidation with aqueous hydrogen peroxide. Chem.Com. 2003, 16, 1977-1986. [CrossRef] [PubMed]

20. Vafaeezadeh, M.; Hashemi, M.M. One pot oxidative cleavage of cyclohexene to adipic acid using silver tungstate nano-rods in a Brønsted acidic ionic liquid. RSC Adv. 2015, 5, 31298. [CrossRef]

Publisher's Note: MDPI stays neutral with regard to jurisdictional claims in published maps and institutional affiliations.

(C) 2020 by the authors. Licensee MDPI, Basel, Switzerland. This article is an open access article distributed under the terms and conditions of the Creative Commons Attribution (CC BY) license (http://creativecommons.org/licenses/by/4.0/). 